\title{
A Comparative Study of the nature of Special Schools for the Blind in Kolkata and Tokyo
}

\author{
Ritwika Laskar \\ Research Student, Department of Education, University of Calcutta, India, email: ritwikalaskar@gmail.com
}

\begin{abstract}
Educationally defined, the blind child is one whose visual loss indicates that he/she should be educated chiefly through the use of Braille and other tactile and auditory materials. Special Schools for the Blind are meant to teach these students self-help skills, daily living skills, vocational skills, and to assist them to manage their own affairs independently during adulthood. Through this study an attempt was made to compare the nature of the Special Schools for the Blind in Kolkata and Tokyo and the facilities provided by these schools. Purposive Sampling technique was used and three Special Schools for the Blind were chosen from both Kolkata and Tokyo. A survey was conducted in these schools and Interview Schedule was used to collect data from the Principal/Teacher-in-Charge. The obtained data were analyzed qualitatively only. Regarding the nature of the Special Schools for the Blind in Kolkata and Tokyo, the data revealed incidences of both similarities and dissimilarities. One striking feature was the lack of uniformity between the schools of Kolkata regarding the availability of facilities. It was observed that quite a few facilities provided in the special schools of Tokyo could be implemented in the schools of Kolkata. The study helped in identifying the strengths and weaknesses of these schools along with determining the scope of their improvement.
\end{abstract}

Keywords: Blind, Kolkata, Nature of the Special Schools, Special Schools for the Blind, Tokyo.

\section{Introduction}

According to Individuals with Disabilities Education Act, USA (IDEA, 1993), “ Visual Impairment including Blindness means an impairment in vision, that even with correction, adversely affects a child's educational performance. The term includes both partial sight (low vision) and blindness." [cited in Mangal; 2007; $p$ 179] ${ }^{1}$

Educationally speaking, those visually handicapped individuals are called blind who use Braille and partially seeing are those who use large print materials and make use of their residual vision as a primary source of their education.

Every individual is born with some inherent potential. It is education which helps a person in realizing his/her potentials and nurturing those. A person who is different from the average is entitled to education which would be suited to his unique needs. Education and proper training enables a person to overcome his/her disability and establish himself/herself as a contributing and an independent member of the society. A blind individual's needs and goals for learning and education are not different from those of the regular learners. It is only the means of achieving these goals which are different. Completely blind students need more systematic plus curricular materials, teaching strategies, assistive technology, etc. Education, in the form and style of Special Education can meet the special needs of these students.

Heward (2000) states, "Special Education is a profession with its own history, cultural practices, tools and research base, focused on the learning needs of exceptional students and adults. But, at the level where exceptional students most meaningfully and frequently contact it, special education is an individually planned, specialized, intensive, goal directed instruction. When practiced most effectively and ethically, special education is also characterized by the use of research-based teaching methods, the application of which is guided by direct and frequent measures of student performance." [cited in Mangal; 2007; $p 29]^{2}$

Special Education is provided mainly in Special Schools. Special Schools for the Blind are meant to take into consideration the unique needs of blind students and provide them with education which would suit their potentials and try to compensate for their disability. A Special School for the Blind generally provides facilities which would help blind students in enhancing their ability to learn.

Through this study an attempt has been made to compare the facilities provided to the blind students in the Special Schools for the Blind in Kolkata and Tokyo. Being a technically advanced country, it is always assumed that Tokyo will have more technically advanced facilities than Kolkata. The researcher intended to find out whether this assumption is true and if it is true then to what extent the facilities provided in the Special Schools for the Blind in Tokyo can be implemented in the Special Schools for the Blind in Kolkata. The researcher also tried to study the similarities and differences in the nature of the Special Schools for the Blind in Kolkata and Tokyo. 


\section{Sample}

Purposive Sampling Technique was used. 3 Special Schools for the Blind from Kolkata and 3 such schools from Tokyo were chosen for the study. Principals/Teacher-in-Charge of these schools were interviewed.

\section{Tools}

Interview Schedule was used to collect information regarding the facilities provided in the Special Schools for the Blind in Kolkata and Tokyo.

The study is delimited with

\section{Delimitation Of The Study}

- Only blind students studying in the Special Schools for the Blind;

- Only the physical facilities and educational facilities provided in the Special Schools for the Blind.

\section{Method Of The Study}

A survey was conducted and the obtained data was analyzed qualitatively only.

\section{Findings}

$\checkmark \quad$ All the 3 Special Schools for Blind in both Kolkata and Tokyo were Government sponsored. By being Government sponsored the Special Schools of Kolkata received financial assistance in the form of hostel contingency and teachers' salary; and on application they received lump grants for maintenance and upkeep of the institution and teaching aids. Non-recurring grants were occasionally provided. But, in Tokyo, all the Special Schools were run by the Government. The entire cost of running the institution was borne by the Government.

$\checkmark \quad$ The study found out that all the 3 Special Schools in Kolkata were registered under the Department of Mass Education and Extension. But, in Tokyo 2 out of 3 Special Schools were under the Tokyo Metropolitan Board of Education. These Special Schools were bound to follow the rules and regulations laid down by the Metropolitan Board. 1 Special School which was under the University of Tsukuba could follow its own policies.

$\checkmark$ In Tokyo all the 3 Special Schools were co-educational. But, in Kolkata, 2 Special Schools were coeducational and 1 was only for boys.

$\checkmark \quad$ In both Kolkata and Tokyo, 2 Special Schools (CBS and LFB in Kolkata and Hachioji and National in Tokyo) provided education from Preparatory/Kindergarten to class XII. 1 institution (BBA) in Kolkata provided education from class I to class $\mathrm{X}$ and 1 institution (Katsushika) in Tokyo provided education from Preparatory/Kindergarten to class IX.

$\checkmark \quad$ In Kolkata all the 3 Special Schools provided free education for the total school period that is from Preparatory to class X/XII; whereas in Tokyo, in all the 3 Special Schools free education was provided only from class I to class IX which is also the stage of compulsory education.

$\checkmark$ Residential facility was available in all the 3 Special Schools of Kolkata and Tokyo. In Kolkata availing the residential facility was optional in 2 Special Schools (CBS and LFB) and it was compulsory in 1 institution (BBA). In Tokyo, the residential facility was mainly for those students who were in the Junior High School (classes VII - IX), and had to travel a long distance to come to the institution. Students, availing the residential facility, had to pay for their food in advance. Students at the Elementary School (classes I - VI) did not use the residential facility.

$\checkmark$ Vocational Training was provided only to the boys in one Special School (BBA) in Kolkata; in 1 Special School (CBS), it was provided only to the girls, and in 1 Special School (LFB) it was provided to both boys and girls and 1 Special School (Katsushika) did not have a vocational training unit. In both Kolkata and Tokyo, vocational training was provided only after the blind students completed the stage of compulsory education.

$\checkmark$ Transport facility was not available in any of the Special Schools in Kolkata. In Tokyo 2 Special Schools had their own bus. However, it was not compulsory for the students to travel by those buses. In 1 institution transport facility was not available.

$\checkmark$ Toilet facility was available in all the 3 Special Schools of both Kolkata and Tokyo. However, the arrangement of the toilets was different in the Special Schools of Kolkata. In 2 Special Schools (BBA and CBS), there were separate toilet for boys and girls on all the floors, and in 1institution (LFB) the boys' toilet was on the ground floor and the girls' toilet was on the first floor. But, in Tokyo it was seen that in all the 3 Special Schools there were separate toilet for boys and girls on all the floors. 
$\checkmark$ Canteen facility was not available in any of the Special Schools in Kolkata. Boarders had their lunch in the hostel and day scholars carried their own tiffin. In Tokyo, however, all the 3 Special Schools had canteen facility. All the Special Schools in both Kolkata and Tokyo supplied drinking water.

$\checkmark$ The study revealed that both in Kolkata and Tokyo, 1 Special School had a Medical Unit. 2 Special Schools only had provisions of First-Aid. In case of any emergency, students were taken to the nearest hospital.

$\checkmark$ Regarding emergency facility, it was seen that out of the 3 Special Schools in Kolkata, in 1 institution (BBA) there were fire extinguishers on all the floors. Blind students, in this institution, received a lecture once/twice a year on how to deal with emergency situations. Teachers/other staff members were trained in using the fire extinguishers. In 1 institution (LFB) fire extinguishers were available but students did not receive any lesson or training in how to deal with emergency situations. Only the teachers were trained in using the fire extinguishers. In the third institution (CBS) fire extinguishers were not available. In Tokyo, fire extinguishers were available in all the 3 Special Schools. Helmets, to be used during earthquakes, were also kept in all the classrooms. Blind students were given training once a month to deal with fire and earthquake like situations. Once/twice a year, training was also given to deal with situations involving burglary or terrorist attacks.

$\checkmark$ None of the Special Schools in Kolkata had Braille lines inscribed on the floor. But, in Tokyo, all the 3 Special Schools had Braille lines inscribed on the floor. Students were made to follow the Braille lines while walking. This helped in their mobility training.

$\checkmark$ The data revealed that none of the Special Schools in Kolkata had lift facility. But, in Tokyo2 Special Schools had lift facility. However, the blind students in those Special Schools were not allowed to use the lift mainly to make them practice moving up and down the stairs more and facilitate their mobility skills. Only, those blind students who were also orthopedically handicapped were allowed to use the lift.

$\checkmark \quad$ In Kolkata none of the Special Schools had handrails along the walls of the staircase; whereas in Tokyo, all the Special Schools had handrails not only along the walls of the staircase but also along the walls of the entire institution.

$\checkmark$ In all the 3 Special Schools of Tokyo, the name/number of the classroom was inscribed outside each classroom. This allowed the blind students to identify their classrooms independently. But, this facility was not available in any of the 3 Special Schools of Kolkata.

$\checkmark$ Regarding the seating arrangement, it was seen that in Kolkata, 1 institution had a low bench and high bench seating arrangement. 4/5 students sat on one bench. This arrangement restricted the mobility of the blind students. In 2 Special Schools, students sat on separate chairs with high benches. The benches were placed very close to one another restricting the movement of the blind students. In Tokyo, in all the 3 Special Schools the seating arrangement included separate chairs and desks.

$\checkmark$ While in Kolkata, only 1 institution had the provision of keeping the books in the classroom, in Tokyo all the 3 Special Schools had bookshelves within the classrooms so that the required books could be kept in them.

$\checkmark$ Library along with a reading room was found in all the 3 Special Schools of both Kolkata and Tokyo.

$\checkmark$ Separate laboratory for Science subjects was also available in all the Special Schools of both Kolkata and Tokyo.

$\checkmark$ Out of the 3 Special Schools in Kolkata, only 1 institution had a separate laboratory for Social Science subjects. But in Tokyo, all the 3 Special Schools had a separate laboratory for Social Science subjects.

$\checkmark \quad$ In Tokyo all the 3 Special Schools had a computer laboratory. Only 2 out of 3 Special Schools in Kolkata had a Computer Laboratory. 1 institution did not have a computer laboratory mainly because in that institution computer was not taught as a regular school teaching subject.

$\checkmark$ Music room was available in all the Special Schools of both Kolkata and Tokyo.

$\checkmark$ Playground and swimming pool were available 2 out of 3 Special Schools in Kolkata, but on the other hand in Tokyo all the 3 Special Schools had playground and swimming pool. 1 institution in Kolkata which did not have play ground and swimming pool took the blind students to a nearby ground for sports and a nearby pool for swimming. None of the Special Schools in Kolkata had a gymnasium, but all the 3 Special Schools in Tokyo had a gymnasium.

$\checkmark$ In Kolkata, none of the Special Schools had any specially designed (sponge-coated wall) hall for sports. But, in Tokyo all the Special Schools had hall with sponge-coated walls. The walls of these halls were designed in such a way that even if a blind student collided against it, he/she would not get hurt. Games like basket ball and volley ball were played in those halls. These specially designed walls ensured safety of the blind students.

$\checkmark$ In Kolkata, there was no provision of appointing more than one teacher or dividing a particular class into sections in case the number of students in that exceeded the maximum limit. In the Special Schools of Tokyo such a provision existed. 


\section{Interpretation}

$>$ In Kolkata, the government only looked into the financial aspect, but in Tokyo, the Government was more involved as it looked into the running of the Special Schools.

For all the three Special Schools under the Department of Mass Education and Extension in Kolkata, it was compulsory to follow the rules and regulations laid down by this body regarding admission of students. In Tokyo, as well, there was such a compulsion but only for those two Special Schools which were under the Tokyo Metropolitan Board of Education.

$>$ In Tokyo, after completing nine years of free and compulsory education, students could either pursue higher studies or any vocation. In case, they wished to pursue higher education then they had to pay the tuition fee. But in Kolkata, education was provided for free for the entire school period even after completing the compulsory school going stage. Therefore in Kolkata, it was financially less burdening for the blind students if they wished to pursue higher education.

$>$ In the Special Schools of Tokyo, there was no compulsion on the students to use the residential facility in any of the Special Schools. But, in Kolkata, one institution made it compulsory.

$>$ Even though vocational training facility was provided in all the three Special Schools in Kolkata and only in two Special Schools in Tokyo, yet it was more convenient in Tokyo, because students, whether boys or girls, who were studying in Hachioji or National, could continue with their vocational training in those Special Schools only. But in Kolkata CBS provided vocational training only to girls. So, those boys who were studying in this school had to shift either to LFB or BBA if they wished to receive vocational training.

$>$ Regarding transport facility, the difference between the Special Schools of Kolkata and Tokyo was quite stark. Even though optional, yet the facility was provided at least in two of the Special Schools in Tokyo. But, in the Special Schools of Kolkata this facility was not provided at all.

$>$ Basic facilities like toilet and canteen were uniformly available in the Special Schools of Tokyo, where as in Kolkata differences were noticed within the Special Schools.

> Provisions regarding medical facility were similar in the Special Schools of both Kolkata and Tokyo.

$>$ Emergency facilities were equally available in all the Special Schools of Tokyo. Blind students were also trained in dealing with emergency situations. In the Special Schools of Kolkata, on the other hand, emergency facilities were not similar in all the Special Schools and Blind students were not given any training in dealing with emergency situations. As a result, the blind students studying in the Special Schools of Tokyo were better trained in dealing with emergency situations than in the Special Schools of Kolkata.

$>$ In Tokyo, throughout the city, Braille lines were inscribed on the roads. Blind students, by following the lines while walking within the institution got familiarized with the conditions outside the institution. But, in Kolkata, there was no such provision and as a result, Braille lines were not inscribed on the floors within the institution.

> Though the Special Schools in Tokyo did not allow the blind students to use the lift, yet at least two Special Schools had the facility. But, in the Special Schools of Kolkata, the lift facility was not available at all.

$>$ Blind students in the Special Schools of Tokyo were trained to hold the handrails while walking, so that they do not fall. This ensured their safety and made them more independent. There was no chance of them falling down the stairs. But, in the Special Schools of Kolkata, the students often had to take help of their low-vision peers while moving up and down the stairs.

$>$ In the Special Schools of Tokyo blind students could themselves locate their classrooms easily by following the Braille inscriptions outside each room. But, in the Special Schools of Kolkata this facility was completely missing. Blind students, therefore, had to rely on their low-vision peers.

$>$ The seating arrangement was similar in all the Special Schools of Tokyo, but in Kolkata there were differences within the Special Schools. 
$>$ It was more convenient for the blind students in the Special Schools of Tokyo than in the Special Schools of Kolkata because they did not have to carry the voluminous books. In the Special Schools of Kolkata, students had to bring the books from the library and also put those back after the class was over.

$>$ The availability of library with a reading room and separate laboratory for Science subjects was similar in all the Special Schools of both Kolkata and Tokyo.

> The availability of a separate laboratory for Social Science subjects and Computers was uniform in the Special Schools of Tokyo. But, it was not so in the Special Schools of Kolkata.

$>$ Some of the facilities like availability of music room were similar in the Special Schools of both Kolkata and Tokyo. But, some facilities like availability of playground, swimming pool and gymnasium were not similar in the Special Schools of Kolkata and Tokyo. While in Tokyo all the Special Schools provided a swimming pool, gymnasium and a play ground, but in Kolkata two Special Schools provided these facilities. However, the third institution which did not have a play ground and a swimming pool sometimes took the students to a nearby ground and lake to compensate for the lack of these facilities and ensure that blind students studying this institution were not deprived.

$>$ Blind students in the Special Schools of Tokyo could play without any fear of getting hurt.

$>$ It was easier for the teachers in the Special Schools for the Blind in Tokyo to pay individual attention to the blind students.

\section{Concluding Observations}

$\checkmark \quad$ Like in Tokyo, all the Special Schools for the Blind in Kolkata should be made co-educational to ensure equal opportunity of education to both boys and girls. However, if turning an existing boys' school into coeducation is difficult then at least an effort should be made to start another special school for girls. Otherwise, the choice of special schools for blind girls in Kolkata is very limited.

$\checkmark$ In Kolkata, the Preparatory stage was only of one year that too in only two institutions. As was prevalent in Tokyo, the Preparatory stage should be increased to three years to give the blind students exposure to educational environment for a longer period of time. In order to increase the duration of the Preparatory stage the institutions in Kolkata would need a lot of financial assistance to improve their educational and infrastructural facilities. The Government has to take an initiative in this respect. If initially, increasing the duration of the Preparatory stage to three years seems difficult then it should at least be increased to two years and gradually to three years.

$\checkmark \quad$ Vocational training facility should be provided in all the Special Schools for the Blind in Tokyo. In Kolkata all the Special Schools for the Blind should provide vocational training facility to both boys and girls instead of only to the boys or only to the girls.

$\checkmark$ Transport facility should be provided in all the Special Schools of both Kolkata and Tokyo. However, using this facility should be kept optional.

$\checkmark \quad$ There should be separate toilet for boys and girls on all the floors in the Special Schools of Kolkata to ensure the convenience of blind students. Like in the Special Schools of Tokyo, canteen facility should be started in the Special Schools of Kolkata.

$\checkmark \quad$ All the Special Schools in both Kolkata and Tokyo should have a medical unit and the health of the blind students should be regularly monitored.

$\checkmark$ Emergency facilities should be uniformly available in all the Special Schools of Kolkata. At least fire extinguishers should be made available and teachers should be trained in using those. Blind students should be made aware of emergency situations and also told how to deal with those. In the Special Schools of Tokyo, such talks and lectures were held regularly and this practice should also be started in the Special Schools of Kolkata. 
$\checkmark \quad$ Lift facility should be made available in all the Special Schools of Kolkata and in that particular institution of Tokyo which did not have a lift. This should be done to make the blind students familiar with using a lift. However, they should not be allowed to use it regularly as it would hamper their mobility training.

$\checkmark \quad$ There should be handrails along the walls of the staircase in the Special Schools of Kolkata. This would ensure independence of the blind students. They can hold these handrails while moving up and down the stairs and walk freely without any fear of falling down. The name/number of each classroom should be inscribed in Braille outside the respective rooms. This would enable blind students to identify the rooms independently without having to ask their low-vision peers.

$\checkmark$ At present only one Special School in Kolkata has the provision of keeping books in the classroom. Therefore, like in Tokyo, all the Special Schools in Kolkata should have the provision of keeping books within the classroom so that blind students do not have to carry the voluminous Braille books to and from the library every day.

$\checkmark \quad$ All the Special Schools in Kolkata should have a separate laboratory for Social Science subjects and the teaching aids for Social Science subjects should be properly displayed. Teaching aids should also be made easily available to the blind students.

$\checkmark$ It is important that all the Special Schools in Kolkata provide similar facilities to the blind students.

$\checkmark \quad$ In Tokyo, all the Special Schools for the blind admitted blind students with other disabilities. Infrastructural facilities of the institutions of Kolkata should be improved and provisions should be made to admit blind students with other disabilities. Teachers have to be specially trained to deal with these students.

$\checkmark$ The Government has to take an active part in helping these Special Schools. (For example: in order to accommodate a blind child who is also orthopedically handicapped, ramp with handrails and lift become mandatory. Similarly, in order to accommodate blind students who are also mentally retarded the curriculum needs to be modified.)

$\checkmark \quad$ Just like the practice in the Special Schools of Tokyo, similarly in the Special Schools of Kolkata provisions should be made to either divide the class into sections or appoint two teachers in case the number of students in a particular class exceeded the maximum limit. This would enable the teachers to pay more attention to the needs of the students.

\section{References}

[1]. S.K. Mangal, Visually Impaired Children, in Educating Exceptional Children an Introduction. (Delhi: PHI, 2007$) 179-181$.

[2]. Ibid. Concept and Provisions of Special Education, 29-31.

[3]. M. Bhargava, Introduction to Exceptional Children in Exceptional Children an Introduction.. (New Delhi: Sterling, 1994) 7-9.

[4]. M. Dash, Special Education, in Education of Exceptional Children. (New Delhi: Atlantic , 2007) 19-20, 26.

\section{ACRONYMS}

BBA

CBS

HACHIOJI

IDEA

KATSUSHIKA

LFB

NATIONAL

\author{
: Blind Boys' Academy \\ : Calcutta Blind School \\ : Tokyo Metropolitan School for the Blind, Hachioji \\ : Individuals with Disabilities Education Act \\ : Tokyo Metropolitan School for the Blind, Katsushika \\ : Lighthouse for the Blind \\ : Tsukuba University School for the Blind
}

